\title{
The quality of berries of promising blackberry varieties in the conditions of the Tambov region
}

\author{
D.M. Bryksin ${ }^{1,2, *}$, and S.A. Kolesnikov ${ }^{1}$ \\ ${ }^{1}$ LLC SPC "Agropishcheprom", 393760 Michurinsk, Russia \\ ${ }^{2}$ FSBSI "Federal Research Center n. a. IV. Michurin”, 393774 Michurinsk, Russia
}

\begin{abstract}
Blackberry is a new berry crop of industrial horticulture in the central part of Russia. More than 20 blackberry varieties were collected at the experimental sites of the SPC "Agropishcheprom". The paper presents the results of the study of 11 modern blackberry varieties. During preparation for winter, the plants were covered with covering material, and therefore, no winter damage was found during the years of research. A fluctuation in the accumulation of positive temperatures during the period of fruit formation and maturation, affecting the biochemical parameters and taste of fruits, was revealed. There is also a difference in the amount of precipitation over the years, which affects the average fruit weight. Thus, in 2020, during the formation and maturation of the fruits, $40 \%$ less precipitation fell in comparison with 2019, which led to a decrease in the average fruit weight. As a result of the research, the varieties were grouped according to maturation period, fruit average weight and taste. Selected varieties for use in breeding for large-fruited are the following: Natchez, Karaka Black, Black Butte and Triple Crown. Loch Maree, Natchez, Polar, Triple Crown, Black Butte and Karaka Black varieties were characterized by high taste qualities.
\end{abstract}

\section{Introduction}

Blackberry is a quite new crop for industrial gardening in Russia. Its major plantations are located in the southern regions, which is explained by the low level of frost resistance of most varieties. The main advantage of the crop is the possibility of obtaining high yields under certain agro technical conditions that blackberry needs. Large berries that attract customers by their appearance often contribute to an increase in demand and even their shortage during the maturation period, and the resistance of the crop to diseases and pests eliminates chemical treatments and contributes to the production of environmentally safe products. In comparison with raspberries, the transportability of blackberries is much higher, and the ease of reproduction and the annually growing demand for fruits and processed products makes blackberries economically attractive for use on an industrial scale.

\footnotetext{
${ }^{*}$ Corresponding author: lonicera.konf@mail.ru
} 
The appearance on the market of new promising highly productive foreign varieties with improved fruit quality, including the biochemical composition, contributes to the intensive development of industrial crop cultivation. Blackberry fruits contain a whole complex of biologically active substances that have a tonic, anti-inflammatory, antiatherosclerotic effect on the human body [1-5].

Abroad, breeding work with the crop has been carried out for more than 170 years [6]. To date, there are many promising varieties of American, English, and Polish selection, successfully cultivated in Russia not only on the home grounds, but also on production sites. The beginning of breeding work on blackberry in Russia was laid by I.V. Michurin at the beginning of the XX century, creating the varieties Enorm, Uraniya, Vostochnaya, Krasnaya, Izobilnaya and Texas. However, only the last two varieties have become widespread $[7,8]$. Active work on the development of new blackberry varieties is carried out in the FSBSI VNIISPK, where a number of promising seedlings-candidates for varieties are identified [9]. The State Register of Breeding Achievements of the Russian Federation for 2020 includes 5 blackberry varieties [10]. The priority areas of blackberry breeding in Russia are the production of winter-hardy, large-fruited, highly productive varieties with an improved taste range of fruits. Breeding for spinelessness and permanent flowering capacity is also an important task [11, 12]. The purpose of this work was to evaluate promising blackberry varieties in terms of large-fruiting and taste qualities, the content of sugars and acids in the fruit, followed by the selection of genetic sources for further breeding.

\section{Materials and methods}

The research was carried out in 2019-2020 at the experimental site of the Department of genetic collections and breeding of fruit and berry crops of the SPC "Agropishcheprom" of the 2017 year of planting and the Biochemistry laboratory of the SPC "Agropishcheprom". The objects of research were 11 blackberry varieties of American, English, Polish and Yugoslavian breeding. The methodological basis of the work was the "Program and methodology of variety study of fruit, berry and nut crops" [13]. The study of the biochemical composition of blackberry fruits included the determination of total sugars according to Bertrand (GOST 8756.13 - 87), the content of titrated acids (total acidity) - by the potentiometric method. The prototypes are placed in a well-lit site. Planting scheme 4.0 $\mathrm{x} 1.5 \mathrm{~m}$. The plants are placed on a trellis. In preparation for winter, the plants were covered with a white covering material with a density of $80 \mathrm{~g} / \mathrm{m}^{2}$. The soil of the site is represented by low-humus chernozem, medium-alkaline, deep medium-loamy.

\section{Results and discussion.}

Blackberry crop is of interest due to the high potential of berries use, both fresh and processed in the food industry. The main requirements for blackberries on the market are transportability, attractiveness of appearance and large fruit, as well as taste.

2019 and 2020 were favorable for the development of experimental blackberry plants. When covering plants for the winter with covering material, after overwintering, no winter damage was found in the studied varieties. The general condition of the registered plants, the degree of flowering and fruiting was estimated at 5.0 points. As a result of the conducted research, the varieties were grouped into early-ripening, mid-ripening and lateripening varieties. Among the studied blackberry samples, $36 \%$ of the varieties were included in the group of early-ripening (July 16-22). The beginning of their maturation was noted at the sum of positive temperatures of $1767-1884^{\circ} \mathrm{C}$ (Table 1). $46 \%$ of the varieties 
maturing at the sum of positive temperatures equal to $2136-2240^{\circ} \mathrm{C}, 18 \%$ of the varieties with the beginning of maturation at the sum of positive temperatures of $2457-2798^{\circ} \mathrm{C}$ are classified as mid-ripening (August 6-12).

Table 1. Grouping of blackberry varieties by maturation period.

\begin{tabular}{|c|c|c|c|}
\hline $\begin{array}{l}\text { Maturation } \\
\text { period }\end{array}$ & $\begin{array}{lll}\text { Early } & (16 . V I I & - \\
22 . V I I) & & \end{array}$ & $\begin{array}{lll}\begin{array}{l}\text { Medium } \\
\text { 2.VIII) }\end{array} & \text { (6.VIII } \\
\end{array}$ & $\begin{array}{l}\text { Late (22.VIII - } \\
\text { 10.IX) }\end{array}$ \\
\hline Variety & $\begin{array}{l}\text { Brzezina, Black } \\
\text { Butte, Natchez, } \\
\text { Karaka Black. }\end{array}$ & $\begin{array}{l}\text { Helen, Triple Crown, } \\
\text { Polar, } \\
\text { Bestrna, Loch Mareanska }\end{array}$ & $\begin{array}{l}\text { Himalaya, } \\
\text { Orcan. }\end{array}$ \\
\hline
\end{tabular}

In 2019, during the period of fruit formation and ripening, the highest amount of precipitation was observed $(164 \mathrm{~mm})$ compared to $2020(99 \mathrm{~mm})$ (Figure 1).

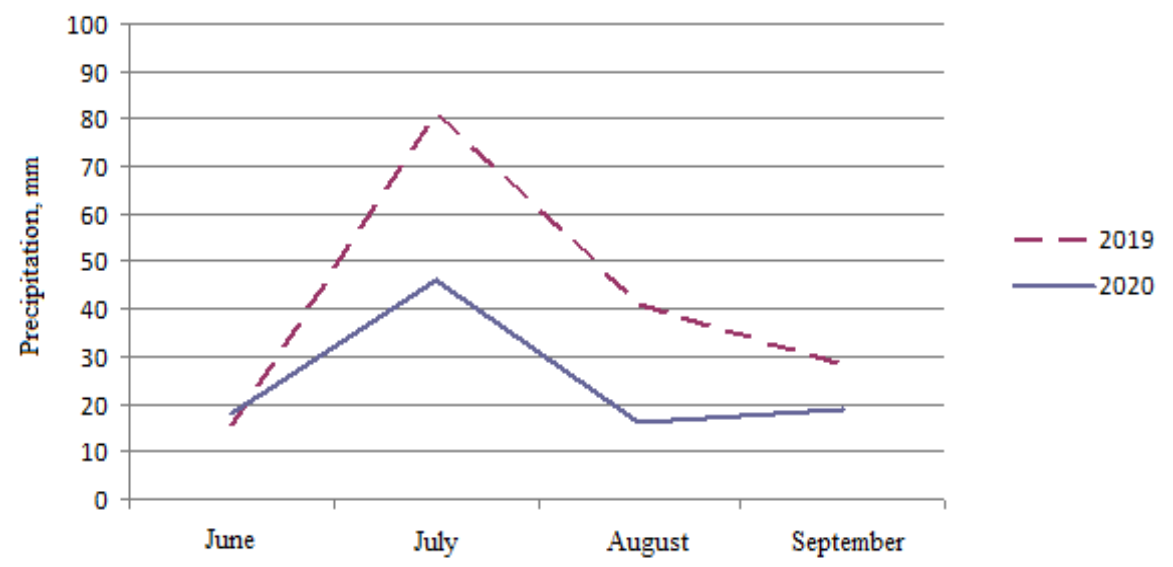

Fig. 1. The amount of precipitation during the period of formation and maturation of blackberry fruits (2019-2020).

The average air temperature for the period of formation and maturation of blackberry fruits in 2019 was lower by $1.6^{\circ} \mathrm{C}$ and amounted to $18.2^{\circ} \mathrm{C}$, in $2020-19.8^{\circ} \mathrm{C}$. There was also a difference in the accumulation of positive temperatures. In 2019, their sum for the above period was $1964^{\circ} \mathrm{C}$, in $2020-2278^{\circ} \mathrm{C}$ (Figure 2 ).

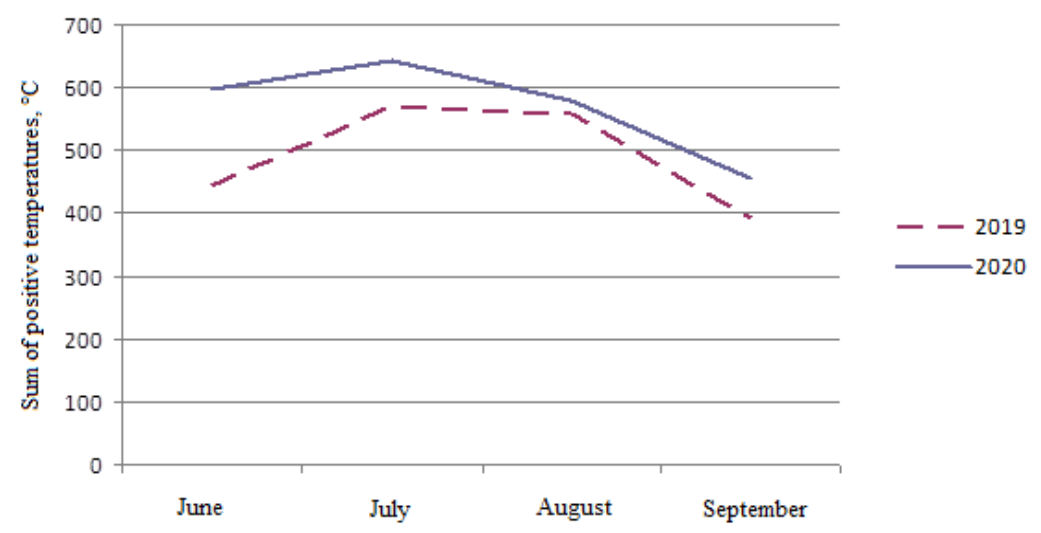

Fig. 2. The sum of positive temperatures accumulated during the period of formation and maturation of blackberry fruits (2019-2020). 
This largely explains the higher average fruit weight in 2019 and the tasting score in 2020. On average, the varieties Natchez, Karaka Black, Black Butte and Triple Crown were among the most large-fruited, over the years of research (Table 2).

Table 2. Estimation of blackberry fruit weight (g), 2019-2020

\begin{tabular}{|c|c|c|c|c|c|c|c|}
\hline \multirow[b]{2}{*}{ Variety } & \multicolumn{3}{|c|}{2019} & \multicolumn{3}{|c|}{2020} & \multirow{2}{*}{$\begin{array}{c}\text { Average fruit } \\
\text { weight on } \\
\text { average for 2019- } \\
2020 .\end{array}$} \\
\hline & $\min$ & $\max$ & average & $\min$ & $\max$ & average & \\
\hline \multicolumn{8}{|c|}{ Early-ripening varieties } \\
\hline Natchez & 10.1 & 12.9 & 11.2 & 9.4 & 11.6 & 10.6 & 10.9 \\
\hline Karaka Black & 8.7 & 13.0 & 10.4 & 8.1 & 12.2 & 10.5 & 10.5 \\
\hline Black Butte & 10.2 & 12.9 & 10.7 & 8.5 & 12.0 & 10.1 & 10.4 \\
\hline Brzezina & 4.2 & 5.3 & 4.5 & 3.6 & 5.0 & 4.2 & 4.4 \\
\hline \multicolumn{8}{|c|}{ Mid-ripening varieties } \\
\hline Triple Crown & 10.1 & 11.7 & 10.6 & 9.5 & 10.3 & 9.3 & 10.0 \\
\hline $\begin{array}{l}\text { Cacanska } \\
\text { Bestrna }\end{array}$ & 6.9 & 9.7 & 8.2 & 6.6 & 8.4 & 7.7 & 8.0 \\
\hline Helen & 5.0 & 6.4 & 5.5 & 4.5 & 6.0 & 5.2 & 5.4 \\
\hline Polar & 4.0 & 6.0 & 4.9 & 3.7 & 5.4 & 4.5 & 4.7 \\
\hline Loch Maree & 3.9 & 5.9 & 4.7 & 3.4 & 5.1 & 4.3 & 4.5 \\
\hline \multicolumn{8}{|c|}{ Late-ripening varieties } \\
\hline Himalaya & 4.5 & 5.3 & 4.7 & 4.1 & 4.2 & 4.1 & 4.4 \\
\hline Orcan & 3.5 & 4.6 & 3.8 & 2.9 & 3.8 & 3.4 & 3.6 \\
\hline LSD 05 & - & - & 1.6 & - & - & 0.9 & 1.2 \\
\hline
\end{tabular}

Studies of the biochemical composition of blackberry fruits are conducted abroad Italy, the United States, in Russia: Samara and Orel regions, the Republic of Dagestan, the Republic of Adygea, as well as in the Republic of Belarus [14, 15 - 19]. Organic acids are an important component that determines the taste qualities of fruits, which determine the high acidity, the range of which varied over the years. Thus, in 2019, the titratable acidity index was higher compared to 2020 (Table 3).

Table 3. Characteristics of blackberry fruits in terms of titratable acidity (\%), 2019-2020

\begin{tabular}{|l|c|c|c|}
\hline Variety & $\mathbf{2 0 1 9}$ & $\mathbf{2 0 2 0}$ & average \\
\hline \multicolumn{4}{|c|}{ Early-ripening varieties } \\
\hline Karaka Black & 2.11 & 2.08 & 2.10 \\
\hline Brzezina & 2.01 & 1.97 & 1.99 \\
\hline Black Butte & 1.67 & 1.53 & 1.60 \\
\hline Natchez & 1.41 & 1.27 & 1.34 \\
\hline \multicolumn{4}{|c|}{ Mid-ripening varieties } \\
\hline $\begin{array}{l}\text { Cacanska } \\
\text { Bestrna }\end{array}$ & 1.83 & 2.04 & 1.94 \\
\hline Polar & 1.47 & 1.22 & 1.35 \\
\hline Helen & 1.62 & 1.44 & 1.32 \\
\hline Triple Crown & 1.20 & 1.08 & 1.14 \\
\hline Loch Maree & 1.21 & 1.07 & 1.11 \\
\hline \multicolumn{4}{|c|}{ Late-ripening varieties } \\
\hline Orcan & 2.34 & 2.08 & 2.21 \\
\hline Himalaya & 2.23 & 2.14 & 2.19 \\
\hline LSD 05 & 0.19 & 0.16 & 0.17 \\
\hline
\end{tabular}

The influence of weather conditions during the period of fruit formation and maturation on the accumulation of sugars in the fruits of the studied blackberry varieties was also 
revealed. Due to the high level of the sum of positive temperatures and the minimum amount of precipitation that fell during the period of fruit formation and maturation, the indicator of the sum of sugars was higher in 2020, and for the varieties Polar, Natchez and Loch Maree it was the maximum (table 4).

Table 4. Characteristics of blackberry fruits by sugar content (\%), 2019-2020

\begin{tabular}{|c|c|c|c|}
\hline Variety & 2019 & 2020 & average \\
\hline \multicolumn{4}{|c|}{ Early-ripening varieties } \\
\hline Natchez & 11.31 & 12.69 & 11.83 \\
\hline Karaka Black & 10.93 & 11.87 & 11.40 \\
\hline Brzezina & 10.42 & 11.84 & 11.13 \\
\hline Black Butte & 9.22 & 10.07 & 9.65 \\
\hline \multicolumn{4}{|c|}{ Mid-ripening varieties } \\
\hline Polar & 12.47 & 13.05 & 12.76 \\
\hline Loch Maree & 11.07 & 12.34 & 11.71 \\
\hline Triple Crown & 10.69 & 11.75 & 11.22 \\
\hline Helen & 10.35 & 11.18 & 10.77 \\
\hline Cacanska Bestrna & 10.12 & 10.81 & 10.47 \\
\hline \multicolumn{4}{|c|}{ Late-ripening varieties } \\
\hline Himalaya & 8.04 & 8.76 & 8.40 \\
\hline \multicolumn{4}{|c|}{ continuation of table 4 . } \\
\hline Orcan & 7.69 & 8.37 & 8.03 \\
\hline LSD 05 & 0.47 & 0.32 & 0.41 \\
\hline
\end{tabular}

The combination of sugar and acids is characterized by a sugar-acid index, varying in the studied varieties from 3.3 p.u. (Orcan) to 11.5 p.u. (Loch Maree). The most harmonious combination (sugar-acid index at the level of 8-11 p.u.) was observed in the varieties Loch Maree, Natchez, Polar and Triple Crown (Table 5).

Table 5. Characteristics of blackberry fruits by sugar-acid index (p.u.), 2019-2020

\begin{tabular}{|l|c|c|c|}
\hline Variety & 2019 & 2020 & average \\
\hline \multicolumn{4}{|c|}{ Early-ripening varieties } \\
\hline Natchez & 8.0 & 10.0 & 9.0 \\
\hline Black Butte & 5.5 & 6.6 & 6.1 \\
\hline Brzezina & 5.2 & 6.0 & 5.6 \\
\hline Karaka Black & 5.2 & 5.7 & 5.5 \\
\hline \multicolumn{4}{|c|}{ Mid-ripening varieties } \\
\hline Loch Maree & 9.2 & 11.5 & 10.4 \\
\hline Triple Crown & 9.8 & 9.9 & 9.9 \\
\hline Polar & 8.5 & 10.7 & 9.6 \\
\hline Helen & 6.4 & 7.8 & 7.1 \\
\hline Cacanska Bestrna & 5.5 & 5.3 & 5.3 \\
\hline \multicolumn{4}{|c|}{ Late-ripening varieties } \\
\hline Himalaya & 3.6 & 4.1 & 3.9 \\
\hline Orcan & 3.3 & 4.0 & 3.4 \\
\hline
\end{tabular}

As a result of open tastings and laboratory studies conducted in the SPC "Agropishcheprom" in 2019 and 2020, the estimated influence of weather conditions during the formation and maturation of fruits on their taste qualities was revealed. Due to less heat accumulation and more precipitation in 2019, the taste indicators of the studied varieties were lower compared to 2020 (Table 6). On average, over the years of the study, the varieties Loch Maree, Natchez, Polar, Triple Crown and Black Butte were identified with a dessert taste, without sourness. Himalaya and Orcan varieties belong to the group of 
samples with late maturation, which is reflected in their taste qualities, apparently due to a lack of heat.

Table 6. Tasting evaluation of blackberry fruits, 2019-2020

\begin{tabular}{|l|c|c|c|}
\hline \multirow{2}{*}{ Variety } & \multicolumn{3}{|c|}{ Taste, score } \\
\cline { 2 - 4 } & 2019 & 2020 & average \\
\hline Natchez & 4.9 & 5.0 & 5.0 \\
\hline Black Butte & 4.6 & 5.0 & 4.8 \\
\hline Karaka Black & 4.4 & 5.0 & 4.7 \\
\hline Brzezina & 4.0 & 4.6 & 4.3 \\
\hline \multicolumn{4}{|c|}{ Mid-ripening varieties } \\
\hline Loch Maree & 5.0 & 5.0 & 5.0 \\
\hline Polar & 5.0 & 5.0 & 5.0 \\
\hline Triple Crown & 4.8 & 4.9 & 4.9 \\
\hline Helen & 4.2 & 4.8 & 4.5 \\
\hline Cacanska Bestrna & 4.1 & 4.7 & 4.4 \\
\hline \multicolumn{4}{|c|}{ Late-ripening varieties } \\
\hline Orcan & 3.8 & 4.3 & 4.1 \\
\hline Himalaya & 3.9 & 4.1 & 4.0 \\
\hline
\end{tabular}

\section{Conclusions}

As a result of the conducted research, it was found that the climatic conditions of 2020 with high air temperatures and insufficient precipitation during the formation and maturation of fruits contributed to a decrease in the average weight of fruits of the studied varieties and an increase in taste qualities. As a result of a comprehensive assessment of fruit quality for cultivation in the Central Chernozem region, the varieties Natchez, Karaka Black, Black Butte and Triple Crown are recommended, which should also be used as sources of large fruit for inclusion in breeding process.

\section{References}

1. S. Şahin, Journal of Food Science, 75(4), 328 (2010)

2. A. Patras, Innovative Food Science \& Emerging Technologies, 10(3), 308 (2009)

3. C. Türkben, Food Analytical Methods, 3(3), 144 (2010)

4. C. Mertz, Agric. FoodChem., 55(21), 8616 (2007)

5. M.Yu. Akimov, Feeding issues, 4, 220 (2020)

6. J.R. Clark, Rev. Bras. Frutic, 46 (2014)

7. I.V. Michurin, Berry crops. V: I.V. Michurin, 432 (1949)

8. V.V. Yakimov, Scientific-prod. ent. "Garden and vegetable garden", 312 (Chelyabinsk. House of Printing, 2010)

9. L.A. Gruner, Fruit growing and viticulture of the South of Russia, 65(5), 46 (2020)

10. State Register of Selection Achievements Authorized for Use for Production Purposes, 680 (2020). URL: http:/ / gossortrf.ru/

11. V.V. Kichina, Program and methodology of fruit, berry and nut crops breeding, 368 (VNIISPK, 1995)

12. L.A. Gruner, Vavilov Journal of Genetics and Breeding, 24(5), 489 (2020) 
13. I.V. Kazakov, Program and methodology of variety study of fruit, berry and nut crops, 374 (VNIISPK, 1999)

14. E.A. Dobrenkov, Proceedings of the international scientific and methodological conference dedicated to the 160th anniversary of VNIISPK, 313 (VNIISPK, 2005)

15. L.V. Legkaya, Fruit growing: scientific works, RUE "Institute of Fruit Growing", 25, $521(2013)$

16. L.A. Gruner, Modern gardening - Contemporaryhorticulture, 4, 38 (2018)

17. B.M. Guseynova, Bulletin of the Samara Scientific Center of the Russian Academy of Science, 8, 89 (2010)

18. N.V. Makarova, Food industry, 4, 25 (2013)

19. L.A. Gruner, Selection and variety breeding of garden crops, 266 (VNIISPK, 1995) 